\title{
Gap Junction-Mediated Astrocytic Networks in the Mouse Barrel Cortex
}

\author{
Vanessa Houades, ${ }^{1,2}$ Annette Koulakoff, ${ }^{1,2}$ Pascal Ezan, ${ }^{1,2}$ Isabelle Seif, ${ }^{3}$ and Christian Giaume ${ }^{1,2}$ \\ ${ }^{1}$ Inserm, U840, and ${ }^{2}$ Collège de France, 75005 Paris, France, and ${ }^{3}$ Université Paris-Sud, EA 3544, 92296 Chatenay-Malabry, France
}

The barrel field of the somatosensory cortex constitutes a well documented example of anatomofunctional compartmentalization and activity-dependent interaction between neurons and astrocytes. In astrocytes, intercellular communication through gap junction channels composed by connexin 43 and 30 underlies a network organization. Immunohistochemical and electrophysiological experiments were undertaken to determine the coupling properties of astrocyte networks in layer IV of the developing barrel cortex. The expression of both connexins was found to be enriched within barrels compared with septa and other cortical layers. Combination of dye-coupling experiments performed with biocytin and immunostaining with specific cell markers demonstrated that astrocytic networks do not involve neurons, oligodendrocytes or NG2 cells. The shape of dye coupling was oval in the barrel cortex whereas it was circular in layer IV outside the barrel field. Two-dimensional analysis of these coupling areas indicated that gap junctional communication was restricted from a barrel to its neighbor. Such enrichment of connexin expression and transversal restriction were not observed in a transgenic mouse lacking the barrel organization, whereas they were both observed in a double-transgenic mouse with restored barrels. Direct observation of sulforhodamine B spread indicated that astrocytes located between two barrels were either weakly or not coupled, whereas coupling within a barrel was oriented toward its center. These observations indicated a preferential orientation of coupling inside the barrels resulting from subpopulations of astrocytes with different coupling properties that contribute to shaping astrocytic networks. Such properties confine intercellular communication in astrocytes within a defined barrel as previously reported for excitatory neuronal circuits.

Key words: connexin; astrocytes; somatosensory cortex; neuroglial interaction; barrel; gap junction

\section{Introduction}

Gap junction-mediated intercellular communication is a typical feature of brain glial cells, in particular, astrocytes. Indeed, in many brain regions and throughout animal life, gap junctional communication (GJC) is extensive and widespread between subpopulations of astrocytes (D'Ambrosio et al., 1998; Blomstrand et al., 2004; Wallraff et al., 2004). Such communicating pathways are provided by junctional proteins named connexins (Cxs), members of a multigenic family (Theis et al., 2005). In astrocytes, two of them prevail: Cx43 and Cx30 (Nagy and Rash, 2000). Interestingly, the expression and the function of these astrocytic Cxs have been demonstrated to be dependent on neuronal activity and survival (Rouach et al., 2000). This observation led to the statement that a loop of interactions occurs between neurons and astrocytes and that these two cell types interact tightly by setting their main mode of communication: synaptic transmission for

Received Nov. 16, 2007; revised March 5, 2008; accepted April 7, 2008.

This work was supported by Inserm and Action Concertée Incitative“Neurosciences Intégratives et Computationnelles" from the Ministère de la Recherche. We thank A.-M. Godeheu for her excellent technical work and Drs. N. Rouach, N. Ropert, P. Gaspar, and G. Bonvento and Prof. E. Welker for helpful comments on this manuscript and fruitful discussion during this work.

Correspondence should be addressed to Dr. Christian Giaume, Inserm, U840, Collège de France, 11 Place Marcelin Berthelot, 75005 Paris, France. E-mail: christian.giaume@college-de-france.fr.

DOI:10.1523/JNEUROSCI.5100-07.2008

Copyright $\odot 2008$ Society for Neuroscience $\quad$ 0270-6474/08/285207-11\$15.00/0 neurons and GJC for astrocytes (Pfrieger and Barres, 1997; Rouach et al., 2004).

Previous reports have demonstrated that GJC studied in astrocytes does not involve all astrocytes and that subpopulations of glial cells with a specific phenotype are not coupled (Wallraff et al., 2004; Houades et al., 2006; Schools et al., 2006). Accordingly, the initially proposed syncytium-like organization of glia (Mugnaini, 1986), suggesting that all glial cells communicate, has to be revised and the term of communicating networks seems to be more appropriate for astrocytes. Based on this, the emerging concept of dynamic interactions between neurons and glial cells should not only be based on presynaptic and postsynaptic neurons interacting with a single astrocyte, as usually done (Volterra and Meldolesi, 2005; Haydon and Carmignoto, 2006). Indeed, another level of neuroglial interaction may occur through the interactions of neuronal circuits with communicating networks of astrocytes (Rouach et al., 2004; Verkhratsky and Toescu, 2006). To address this issue, the definition of the topographic and shaping properties of astrocytic networks in a defined brain structure is first required.

The aim of the present work was to determine the coupling properties and the spatial organization of gap junction-mediated astrocytic networks in layer IV of the primary somatosensory cortex. Indeed, in this cortical region, neurons are arranged in discrete clusters, named "barrels," which receive topographically organized inputs from their respective principal whiskers on the 
contralateral side of the face via the whisker-to-barrel pathway (Woolsey and Van der Loos, 1970). Such anatomofunctional organization offers an ideal model to study how astrocytic networks are organized in reference to neuronal compartments. Here, we report that the expression of the two astrocytic Cxs is enriched in the barrels, compared with the interbarrel areas, the septa. In addition, intercellular diffusion of gap junction-permeable molecules is restricted between two adjacent barrels. This restriction is primarily caused by the low level of coupling in astrocytes located in the septa. In addition, within a barrel dye coupling is oriented toward the center, indicating that intercellular exchanges are favored within a defined barrel rather than between two barrels. These observations suggest that astrocytic networks parallel the columnar compartmentalization of neurons in the somatosensory cortex.

\section{Materials and Methods}

All experiments involving animals have been performed in accordance with the European Community Council Directives of November 24th, 1986 (86/609/EEC) and all efforts have been made to minimize the number of animals used as well as their suffering. They were conducted in conformity with INSERM guidelines. Slices and sections were prepared from $\mathrm{OF} 1$ and $\mathrm{C} 3 \mathrm{H} / \mathrm{HeOuJ}$ mice (Charles River Laboratories, L'Arbresle, France). Transgenic monoamine oxidase A (MAOA) knock-out (KO) mice (Cases et al., 1995), MAOA/5- $\mathrm{HT}_{1 \mathrm{~B}}$ receptor double $\mathrm{KO}$ mice (Rebsam et al., 2002) and glial fibrillary acidic protein-human enhanced green fluorescent protein (GFAP-eGFP) (Nolte et al., 2001) mice were also used. $\mathrm{C} 3 \mathrm{H} / \mathrm{HeOuJ}$ mice were only used as controls for the $\mathrm{KO}$ mice.

Electrophysiology. Postnatal day 5 (P5)-P21 mice were decapitated, and their brains were dissected and placed in ice-cold artificial CSF (ACSF) containing (in mM) $125 \mathrm{NaCl}, 2.5 \mathrm{KCl}, 25$ glucose, $25 \mathrm{NaHCO}_{3}$, $1.25 \mathrm{NaH}_{2} \mathrm{PO}_{4}, 2 \mathrm{CaCl}_{2}$, and $1 \mathrm{MgCl}_{2}$, bubbled with $95 \% \mathrm{O}_{2} / 5 \% \mathrm{CO}_{2}$, $\mathrm{pH}$ 7.4. Coronal brain slices $(300 \mu \mathrm{m})$ containing the somatosensory cortex were cut using a vibratome (VT 1000GS; Leica, Wetzlar, Germany) filled with ice-cold ACSF. The slices were transferred at room temperature $\left(20-22^{\circ} \mathrm{C}\right)$ for $1 \mathrm{~h}$ before being used. Thereafter, the slices were placed in a recording chamber and perfused continuously with oxygenated ACSF, pH 7.4, at a rate of $2 \mathrm{ml} / \mathrm{min}$. The somatosensory cortex and the layer IV neurons were recognized in the recording conditions by visualization of the barrel field (see Fig. $1 A$ ) using an up-right fixed stage microscope (Axioskop FS; Zeiss, Oberkochen, Germany) equipped with Nomarski optics and an infrared video camera (Newvicon C2400; Hamamatsu, Shizouka, Japan). Cells within the barrel cortex were identified as astrocytes based first on morphological criteria and second on electrophysiological properties. The pipette (10-15 M $\Omega$ ) solution contained (in $\mathrm{mm}$ ) $105 \mathrm{~K}$-gluconate, $30 \mathrm{KCl}, 10$ HEPES, 10 phospho-creatine Tris, 4 ATP- $\mathrm{Mg}^{2+}$, 0.3 GTP-Tris, and 0.3 EGTA, adjusted to $\mathrm{pH} 7.3$ with $\mathrm{KOH}$. Whole-cell membrane voltages and currents were amplified by a MultiClamp 700B amplifier, sampled by a Digidata $1322 \mathrm{~A}$ Interface, and patch-clamp recordings $(5 \mathrm{kHz}$ sampling and $3 \mathrm{kHz}$ filtering) were performed with Pclamp9 software (Molecular Devices, Foster City, CA). Series resistances were compensated at $80 \%$. Input resistance $\left(R_{\text {in }}\right)$ was measured in voltage-clamp mode by applying hyperpolarizing voltage pulses $(10 \mathrm{mV}, 150 \mathrm{~ms})$ from a holding potential of $-80 \mathrm{mV}$. To evaluate the level of coupling, either biocytin $(3-4 \mathrm{mg} / \mathrm{ml}$; Sigma, St. Louis, MO) or sulforhodamine B ( $1 \mathrm{mg} / \mathrm{ml}$; Invitrogen, Eugene, OR) were added to the pipette solution before each experiment. Recorded cells were loaded passively with these dyes during $20 \mathrm{~min}$ in current-clamp mode. To inhibit GJC in astrocytes, the slices were pretreated with $100 \mu \mathrm{m}$ carbenoxolone for $15 \mathrm{~min}$ before and during pathclamp recording. After electrophysiological recordings, the slices were fixed at $4^{\circ} \mathrm{C}$ for $12 \mathrm{~h}$ in $4 \%$ paraformaldehyde in PBS, $\mathrm{pH} 7.4$, and then stored in PBS.

Dye diffusion, GJC quantification in brain slices, and cellular phenotype identification. Biocytin detection was performed by incubating the slices in avidin-biotinylated horseradish peroxidase (ABC-Elite; Vector Laboratories, Burlingame, $\mathrm{CA}$ ), reacting with 3.3-diaminobenzidine (Vector
Laboratories) as a chromogen. In some experiments, biocytin detection was combined with immunolabeling for GFAP, S100, NG2, or neuronal nuclei (NeuN) to determine the phenotype of the coupled cells. Briefly, slices were permeabilized and immunoblocked with $0.25 \%$ Triton X-100 and gelatin $(2 \mathrm{~g} / \mathrm{L})$ in PBS for $1 \mathrm{~h}$. Then primary antibodies, mouse monoclonal anti-GFAP (1:500; BD Biosciences, Franklin Lakes, NJ), rabbit anti-S100 (1:4000; BD Biosciences), mouse anti-NG2 (1:500; Millipore Bioscience Research Reagents, Temecula, CA), or mouse monoclonal NeuN (1:500; Millipore Bioscience Research Reagents) were incubated overnight at $4^{\circ} \mathrm{C}$ in Triton/gelatin/PBS. The secondary antibody, Alexa 555- or 488-conjugated goat anti-mouse IgG (1:2000; Invitrogen) or goat anti-rabbit IgG (1:2000; Invitrogen), was applied together with Alexa 555- or 488-conjugated avidin (1:400; Invitrogen) for $2 \mathrm{~h}$ at room temperature. After several washes, the slices were mounted with mounting medium (Fluoromount; Southern Biotechnology, Birmingham, AL) and examined with a confocal laser-scanning microscope (Leica TBCS SP2). In addition to this dye-coupling analysis performed on fixed tissues, in vivo photographs with a digital camera (D70; Nikon, Tokyo, Japan) were achieved on the patch-clamp setup by using sulforhodamine B as an intercellular tracer while the barrels were visualized under Nomarski optics. The superposition of the two images allowed the localization of the injection site and the analysis of the extent of dye spread in relation with the walls of the barrels.

Quantification of GJC, obtained in a double-blind paradigm, was achieved by measuring the distance of biocytin diffusion between the two extreme stained somata according to the perpendicular $(y)$ and parallel $(x)$ axes to the surface of the cortex. Then the area of coupling was obtained by computation of the surface ellipse defined by the two measured parameters, $x$ and $y$.

Tissue preparation, immunofluorescence labeling, and immunohistochemistry. P6 to adult ( $>2$ months) mice were anesthetized, perfused with $\mathrm{PBS}$, and their brains were rapidly removed and frozen in isopentane cooled at $-30^{\circ} \mathrm{C}$. Coronal sections $(20 \mu \mathrm{m})$ were cut on a cryostat, collected on slides, and kept at $-80^{\circ} \mathrm{C}$ until use. Sections through the somatosensory cortex of mice were fixed with $2 \%$ paraformaldehyde in PBS for $30 \mathrm{~min}$ at $4^{\circ} \mathrm{C}$, washed three times with PBS, and preincubated 30 min in PBS containing $0.2 \%$ gelatin and $0.2 \%$ Triton X-100. First, localization of barrels was confirmed in one of the serial sections with a cytochrome oxidase reaction. After this revelation, appropriate sections were selected and then processed for immunohistochemical staining by overnight incubation at $4^{\circ} \mathrm{C}$ with primary antibodies diluted in PBS: rabbit polyclonal anti-Cx43 (1:500; Zymed, San Francisco, CA) or mouse anti-Cx43 monoclonal antibodies (1:500; BD Biosciences); rabbit antiCx30 (1:500; Zymed). Each immunolabeling with antibodies against an astrocytic protein was performed on the same or adjacent slice with mouse anti-NeuN monoclonal antibody (1:500; Millipore Bioscience Research Reagents) to colocalize neuronal organization and astrocytic proteins in barrels. After three washes, slices were incubated for $2 \mathrm{~h}$ at room temperature with the appropriate secondary antibody, Alexa 488conjugated goat anti-mouse IgG (1:2000; Invitrogen) or Alexa 555conjugated goat anti-rabbit IgG (1:2000; Invitrogen). After several washes, slices were mounted in Fluoromount and examined with a microscope equipped with epifluorescence (Eclipse E800; Nikon). Moreover, images were acquired with a confocal laser-scanning microscope (Leica TBCS SP2) equipped with $16 \times, 40 \times$, and $63 \times$ objectives; stacks of consecutive confocal images, taken at intervals of $2 \mu \mathrm{m}, 1 \mu \mathrm{m}$, and 500 $\mathrm{nm}$, respectively, were acquired sequentially with two lasers (argon 488 $\mathrm{nm}$ and helium/neon $543 \mathrm{~nm}$ ) and $Z$ projections were reconstructed using Leica confocal software. Images covering large areas were obtained by assembly of several images captured with a $16 \times$ objective using the photomerge function of Adobe (San Jose, CA) Photoshop software.

Cytochrome oxidase activity was revealed as described by Wong-Riley and Welt (1980). In brief, coronal sections $(20 \mu \mathrm{m})$ were fixed with $2 \%$ paraformaldehyde in PBS for $30 \mathrm{~min}$ at $4^{\circ} \mathrm{C}$, washed three times with PBS. Then, sections were sequentially incubated in phosphate buffer $(0.1$ M), pH 7.4, with $10 \%$ sucrose, $0.2 \%$ cobalt chloride ( $10 \mathrm{~min}$ ), phosphatebuffered sucrose, $0.007 \%$ cytochrome $c, 0.002 \%$ catalase, $0.02 \%$ dimethylsulfoxide, and $0.05 \%$ diaminobenzidine in phosphate-buffered sucrose (all products were purchased from Sigma). 

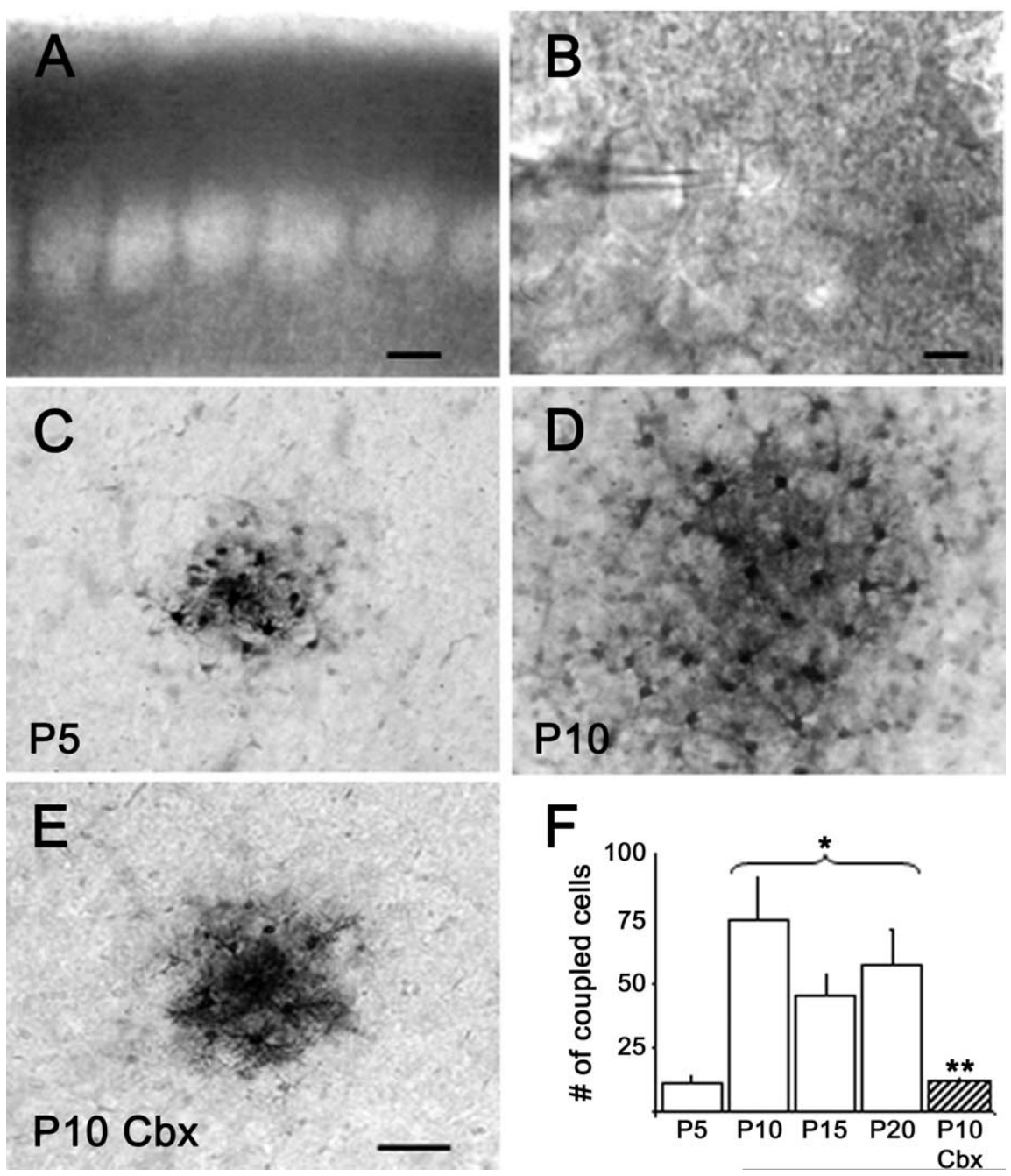

the lack of action potential in response to depolarizing current injections, the absence of spontaneous electrical activity, and the negative resting potential $(<-70$ $\mathrm{mV})$. Furthermore, in voltage-clamp mode, the absence of typical off-set currents indicated that these cells were not oligodendrocytes (Chvatal et al., 1995). When whole-cell recording of a glial cell was performed with a biocytin-filled pipette, this intercellular tracer was detected in surrounding cells after fixation and biocytin revelation (Fig. 1C,D). The number of coupled cells was found to be dependent on the age of the mice. Indeed, it was rather limited at P5 (Fig. 1C) $(11 \pm 3$ cells; $n=6)$, significantly increased at P10 (Fig. 1D) (73 \pm 17 cells; $n=10 ; p<0.01)$, and remained statistically similar at P15 and P20 ( $45 \pm 8$ cells, $n=8$ and $57 \pm 14$ cells, $n=$ 7 , respectively). This intercellular diffusion of biocytin was mediated by gap junction channels, because it was inhibited by carbenoxolone $(100 \mu \mathrm{M}, 15 \mathrm{~min}$ preincubation; $12 \pm 2$ cells; $n=6 ; p<0.01)$, as illustrated for P10 in Figure $1 E$. Moreover, when neurons were recorded in the same area, biocytin was always restricted to the recorded cell $(n=12)$, indicating the lack of neuronal dye coupling at the investigated ages. This developmental study is summarized in the diagram illustrated in Figure $1 F$, where the extent of biocytin diffusion was quantified by the calculation of the number of coupled cells.

To determine the identity of the cells

Figure 1. Dye coupling among astrocytes in the barrel cortex studied at different developmental stages. $\boldsymbol{A}$, Photomicrograph of an acute coronal slice of the somatosensory cortex at P10, showing a field of six barrels observed with Nomarski optics and infrared illumination. $\boldsymbol{B}$, Photomicrograph taken at a higher magnification showing, at the tip of the patch-clamp pipette, an astrocyte selected for recording on the basis of the size and shape of its somata. $C, D$, Two examples of dye coupling in the barrel cortex at P5 and P10 obtained after fixation of the slice and peroxidase revelation of biocytin. $\boldsymbol{E}$, Inhibition of GJC at P10 studied in a slice treated with carbenoxolone (100 $\mu \mathrm{m})$. F, Diagram of the developmental study (P5 to P20) of GJC assessed by biocytin injection in astrocytes. Dye coupling was quantified by counting the number of biocytin-positive cells. Note the large and statistically significant difference in the levels of coupling observed between P5 and P10. The number of experiments ranged from 6 to 10 . ${ }^{*} p<0.05$ between P5 and the other developmental ages using one-way ANOVA, and ${ }^{* *} p<0.01$ between the extent of dye at $\mathrm{P} 10$ in control or with carbenoxolone treatment using unpaired $t$ test. Scale bars: $\boldsymbol{A}, \boldsymbol{E}$ (for $\boldsymbol{E}, \boldsymbol{C}, \boldsymbol{D}), 100 \mu \mathrm{m} ; \boldsymbol{B}, 10 \mu \mathrm{m}$.

Statistical analysis. For each data group, results are expressed as mean \pm SEM and $n$ refers to the number of independent experiments. For statistical analysis of the $x / y$ ratio, resting membrane potential, and input resistance, a one-way ANOVA followed by a Kruskal-Wallis test was used. An unpaired $t$ test was applied to compare the effect of carbenoxolone to the control. Differences are considered significant at ${ }^{\star} p<$ 0.05 and ${ }^{* *} p<0.01$.

\section{Results}

Characterization of astrocytic networks in the barrel cortex Recordings were performed in the primary somatosensory cortex identified by the presence of barrels visualized by infrared video microscopy and differential interference contrast (DIC) optics (Fig. 1A). In addition, control experiments were performed in the same cortical layer from the visual cortex. Glial cells were distinguished from neurons by their small $(<10 \mu \mathrm{m})$ and oval shaped somata (Fig. $1 B$ ). This identification was confirmed by biocytin, indicating that these $\mathrm{NG}$, cells was observed with biocytin, indicating that these $\mathrm{NG}^{+}$cells were not involved in the network revealed by biocytin injection $(n=8)$ (Fig. $2 C, D)$. As reported previously (Houades et al., 2006), GFAP immunoreactivity is very weak in the mouse cortex. Indeed, only few GFAPpositive cells were observed in the area of coupling which explains the low proportion of biocytin- and GFAP-positive cells (28\%; $n=4$ ) (data not shown). Interestingly, when GFAP-eGFP mice were used, the number of eGFP-positive cells was higher than that obtained with GFAP antibody labeling. Using this transgenic mouse, the proportion of biocytin- and eGFP-positive cells reached $60 \%(n=8)$. Finally, when anti-S100 antibody was used, the number of cells positive for biocytin and S100 was increased to $90 \%(n=7)$ as illustrated in Figure 2, E and F. Altogether, these experiments indicate that the intercellular diffusion of the tracer from an identified astrocyte allows visualization of a network of communicating cells that exclude neurons and $\mathrm{NG}^{+}$cells and is 

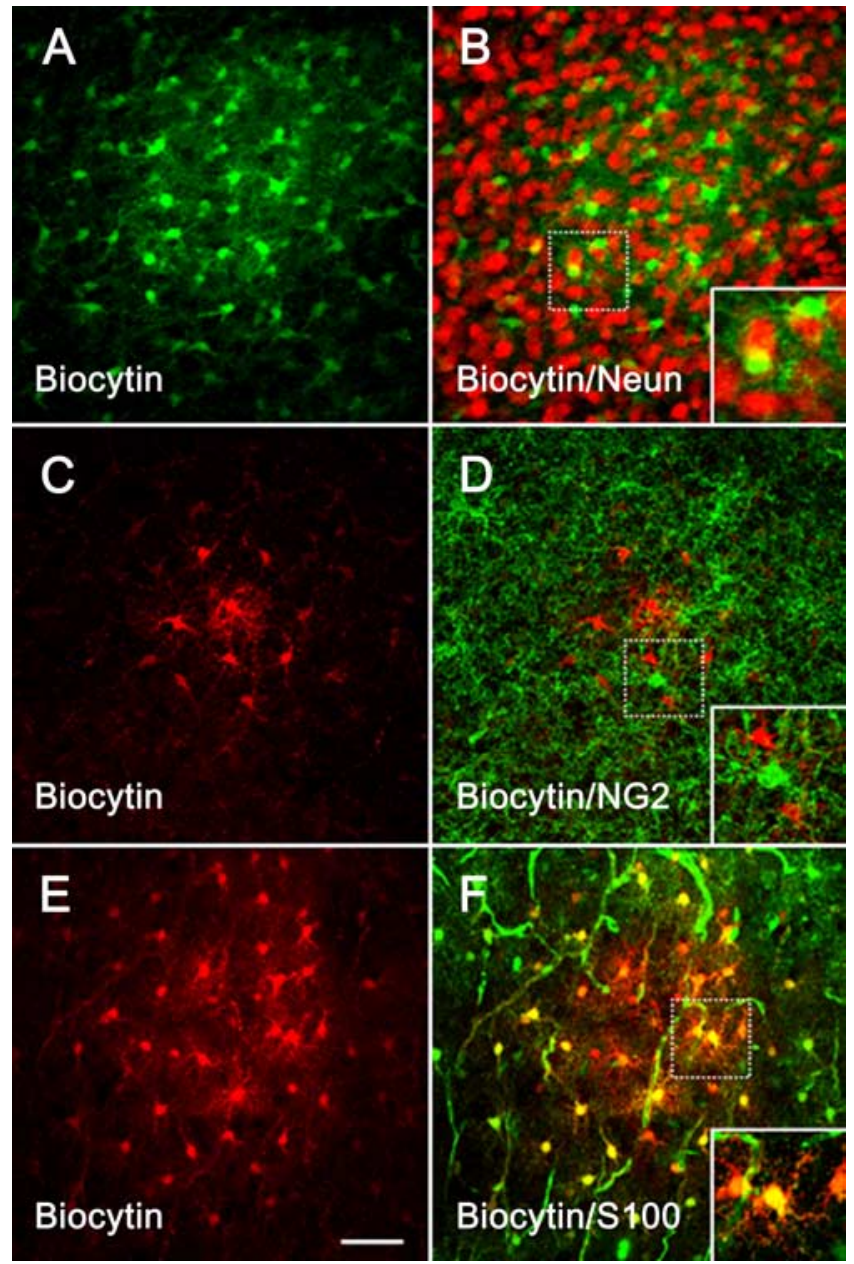

Figure 2. Immunostaining identification of dye-coupled cells. Dye coupling was studied with biocytin injection and postfixation revelation with a secondary antibody coupled to fluorophores selected to be processed with immunohistochemical identification of various brain-cell populations. $\boldsymbol{A}, \boldsymbol{B}$, Dye coupling performed with biocytin (green) and combined with NeuN staining (red) indicates that coupling initiated by the recording from an astrocyte does not involve neurons. The inset demonstrates that the yellow spots observed in $\boldsymbol{B}$ are not caused by colocalization of the two markers, but rather by the superposition of the two distinct stainings resulting from the projection of several confocal plans. C, D, Dye coupling studied with biocytin (red) and combined with NG2 staining (green) indicates that coupling initiated by the recording of an astrocyte does not involve NG2-positive cells. $\boldsymbol{E}, \boldsymbol{F}$, Dye coupling with biocytin (red) and combined with $\mathrm{S} 100$ (green) staining indicates that coupling initiated by the recording of an astrocyte mainly involves $\mathrm{S} 100$-positive cells. Note that as expected from previous reports, this antibody also stains blood vessels. The inset illustrates the colocalization of the two markers. Similar observations were performed in four to eight independent experiments. Scale bar, $50 \mu \mathrm{m}$.

mainly composed of cells identified as astrocytes based on GFAP and S100 antibody staining and using a GFAP-eGFP mouse.

\section{Electrophysiological properties of astrocytes in the barrel cortex}

The analysis of whole-cell recordings indicated the occurrence of three subpopulations of glial cells displaying distinct electrophysiological properties. They were classified as "complex" glia (CGs), "intermediary" glia (IGs), and "passive" astrocytes (PAs). This classification was based on their electrophysiological phenotype, their identification by specific markers as well as their level of GJC and is consistent with the previously proposed classification of glial cells (Schools et al., 2006; Zhou et al., 2006). CGs were characterized by voltage-dependent currents and a strong outward
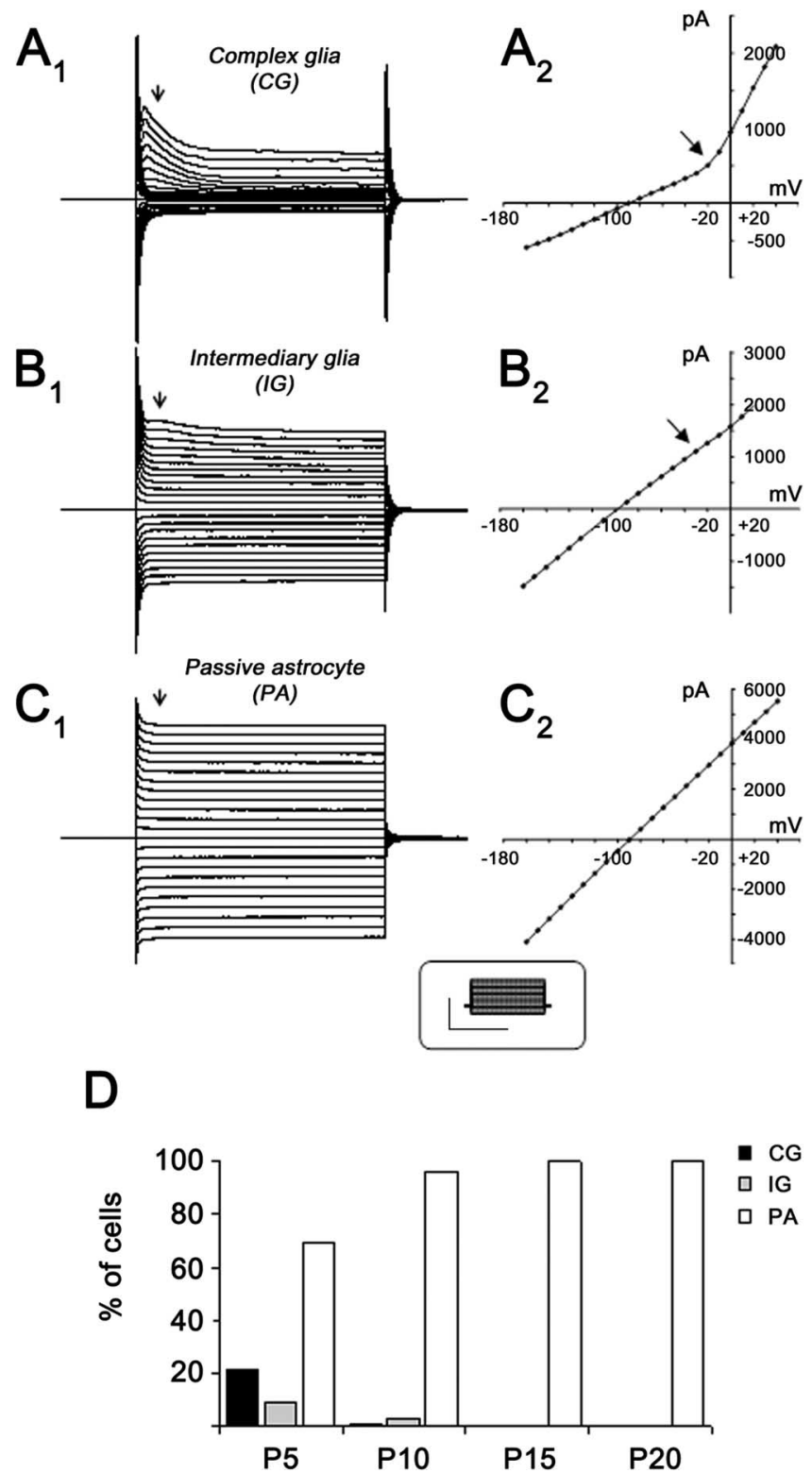

Figure 3. Developmental changes in electrophysiological phenotypes of astrocytes recorded in the barrel cortex. $A_{1}-C_{2}$, Whole-cell current profiles recorded from morphologically identified astrocytes in layer IV of the somatosensory cortex. Voltage steps for the current induction were $150 \mathrm{~ms}$ pulses applied at a holding potential of $-80 \mathrm{mV}$ and ranging from -180 to +40 $\mathrm{mV}$ with $10 \mathrm{mV}$ increments. $A_{1}, A_{2}$, CGs were characterized by a high input resistance and by the activation of inward and outward currents in response to depolarizing steps resulting in a strong outward rectification as illustrated by the plotting of the $I-V$ relationship. $\boldsymbol{B}_{1}, \boldsymbol{B}_{2}$, IGs showed lower input resistance and weaker voltage-dependent currents compared with CGs with a weak change in the slope of the $I-V$ curve. $C_{1}, C_{2}$, PAs exhibited a very low input resistance and a typical linear relationship between current and voltage. $D$, Developmental pattern of astrocytic electrophysiological phenotypes. Note that CGs and IGs were only observed at P5 and P10 in rather low proportion. This diagram was made from $33,131,35$, and 18 cells recorded at P5, $\mathrm{P} 10, \mathrm{P} 15$, and P20, respectively.

rectification (Fig. $\left.3 A_{1}, A_{2}\right)$ associated with a high $R_{\text {in }}(327 \pm 39$ $\mathrm{M} \Omega ; n=5)$ and an average membrane potential of $-78 \pm 5 \mathrm{mV}$ $(n=5)$. IGs were distinguished by their nonlinear currentvoltage $(I-V)$ relationship because of weak but detectable voltage-dependent currents activated by depolarizing pulses (Fig. $\left.3 B_{1}, B_{2}\right)$. Their input resistance was low compared with that of CGs $(47 \pm 10 \mathrm{M} \Omega ; n=12 ; p<0.001)$, whereas their resting membrane potential was significantly more negative $(-88 \pm 2$ 

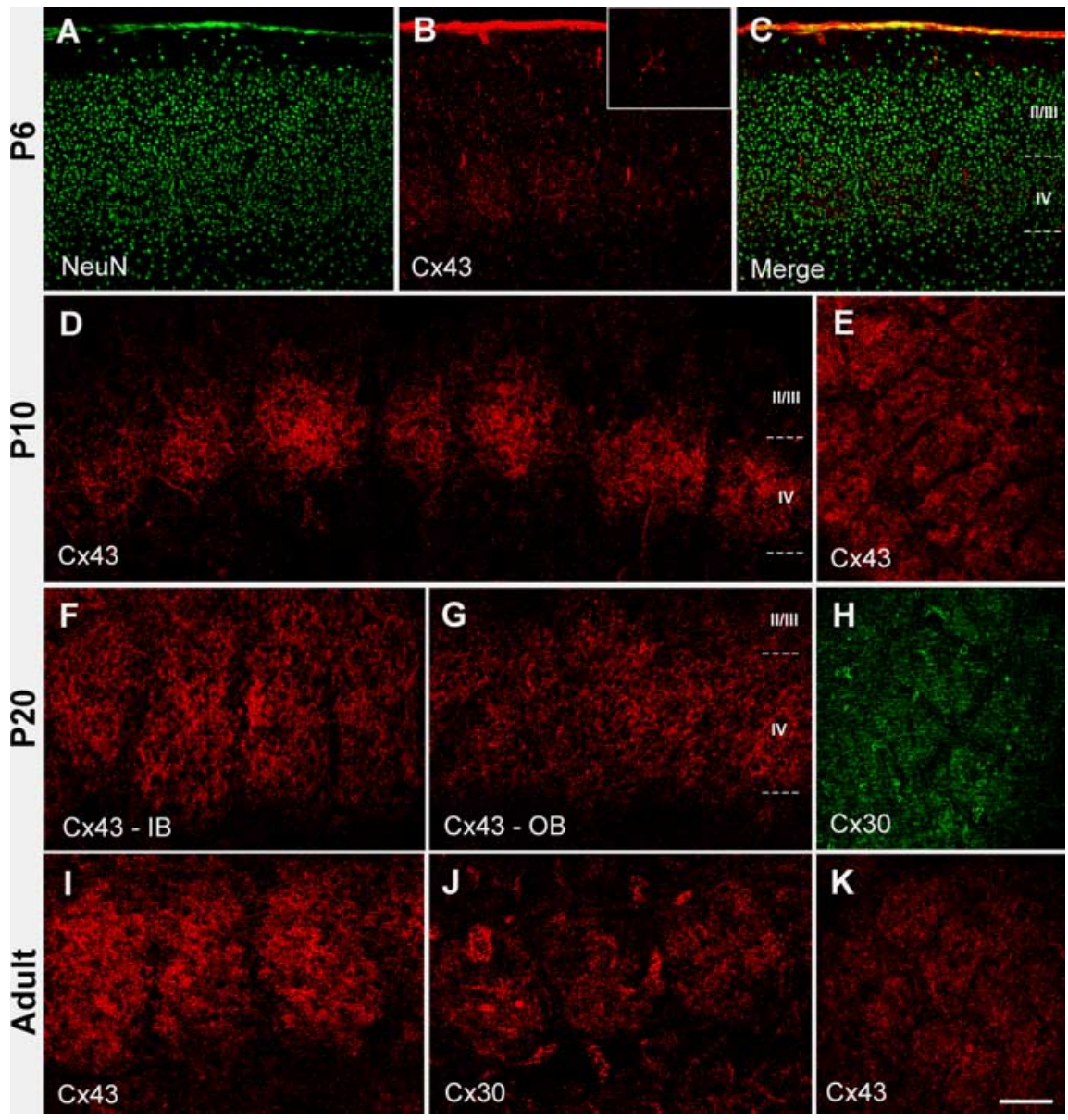

Figure 4. Distribution of $\mathrm{C} x 43$ and $\mathrm{C} \times 30$ in layer IV of the barrel cortex. $A-C$, Double staining of coronal sections from barrel cortex, performed with NeuN (green) and $\mathrm{C} 43$ (red) antibodies, showing that at P6, Cx43 expression was already enriched in the barrels. In the merge $(\boldsymbol{C})$, NeuN staining allowed delineation of the barrel walls. The inset in $\boldsymbol{B}$ illustrates at a higher magnification the pattern of $\mathrm{C} x 43$ staining. At this age, this immunoreactivity was characterized by a diffuse stellate pattern and the presence of few immunoreactive puncta. $\boldsymbol{D}, \boldsymbol{E}$, Single staining of $(x 43$ in coronal $(\boldsymbol{D})$ and tangential $(\boldsymbol{E})$ sections from P10 mouse barrel cortex. $\boldsymbol{F}, \boldsymbol{G}$, Single staining of $\mathrm{C} \times 43$ in coronal sections in $(\boldsymbol{F})$ and out $(\boldsymbol{G})$ of the barrel field (IB and $0 B$, respectively) from $P 20$ mouse. $\boldsymbol{H}$, Single staining of $\mathrm{C} \times 30$ in tangential sections from $\mathrm{P} 20$ mouse barrel cortex. Note that the compartmentalization of $\mathrm{CX}$ expression observed in the barrel cortex is not observed in layer IV of the visual cortex. $\boldsymbol{I}-\boldsymbol{K}$, Single staining of $\mathrm{C} \times 43$ (I, coronal section; $\boldsymbol{K}$, tangential section) and $(\times 30(J)$, indicating that the enrichment of their expression in the barrels is maintained at adult stage. In $\boldsymbol{C}, \boldsymbol{D}$, and $\boldsymbol{G}$, dotted lines delineate the location of the indicated cortical layers. Similar observations were made in three independent experiments performed at the different ages. Scale bar: (in $\boldsymbol{K}) \boldsymbol{A}-\boldsymbol{D}, \boldsymbol{F}, \boldsymbol{G}, \boldsymbol{I}, \boldsymbol{J}, 100 \mu \mathrm{m} ; \boldsymbol{E}, \boldsymbol{H}, \boldsymbol{K}, 140 \mu \mathrm{m}$.

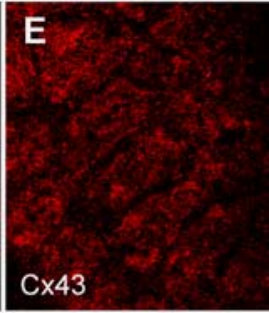

\section{Expression pattern of astrocytic} connexins in the barrel cortex

The pattern of Cx expression was examined at developmental stages similar to those selected for electrophysiology along the present study (Figs. 1, 3) as well as in the adult. Because in vivo astrocytic gap junctions are mainly composed by $\mathrm{Cx} 43$ and Cx30 (Nagy and Rash, 2000; Rouach et al., 2004; Theis et al., 2005), the present study was limited to the analysis of these two Cxs. $\mathrm{Cx} 43$ and $\mathrm{Cx} 30$ distribution was studied by confocal microscopy in coronal and tangential sections of the barrel field of mice at different ages (Fig. 4). At P6, the earliest age analyzed, $\mathrm{Cx} 43$ was detected in layer IV of the barrel cortex, whereas $\mathrm{Cx} 30$ was not detected (data not shown). At this stage, regions enriched in $\mathrm{Cx} 43$ were observed, with a bright punctiform staining of meninges and a staining in layer IV significantly stronger than in other cortical layers. This labeling was not uniform and was found to be enriched within the barrels as delineated by NeuN staining (Fig. $4 A-C$ ). Moreover, the Cx43 immunoreactivity was mostly associated with small processes exhibiting a stellate appearance (Fig. $4 B$, inset) as described previously (Yamamoto et al., 1992). This pattern of immunostaining for Cx43 was not observed at older analyzed ages (supplemental Fig. 1, available at www.jneurosci.org as supplemental material). At P10, Cx43 staining changed and became essentially punctate as in other brain structures (Houades et al., 2006), although its enrichment in the barrels was obvious compared with the septa located between two adjacent barrels (supplemental Fig. $1 A-D$, available at www.jneurosci.org as supplemental material) and to the other cortical layers (Fig. 4E). Cx30 became detectable at P15 with a punctate labeling (supple$\mathrm{mV} ; n=12 ; p<0.01)$. Finally, most of the recorded glial cells were PAs characterized by a strict linear $I-V$ relationship (Fig. $\left.3 C_{1}, C_{2}\right)$ with a low input resistance $(31 \pm 2 \mathrm{M} \Omega ; n=267)$ and a membrane potential similar to that of IGs $(-85 \pm 1 \mathrm{mV} ; n=$ 267). Along this study, CGs and IGs were only found at P5 and $\mathrm{P} 10$, with a decrease in incidence with time and after P10 only PAs were recorded (Fig. 3D). Because of the overall low number of CGs and IGs, their coupling properties were quantified by pooling together these two ages. For CGs, when the patch pipette was withdrawn, in three experiments over five the cell integrity was preserved. Among these three cells, two were positive for the NG2 antibody. In these three experiments, the biocytin loading of the recorded cell was not associated with dye coupling in adjacent cells. For IGs, two cells of four were dye-coupled (38 and 53 coupled cells). Finally, compared with the other glial subpopulations, PAs presented the highest incidence of coupling with $88 \%$ $(n=8)$ at P5, 95\% $(n=40)$ at P10, 96\% $(n=24)$ at P15, and $100 \%(n=10)$ at P20. Moreover, as illustrated in the diagram of Figure 1, the level of coupling of the recorded PAs was dependent on the age with a significant increase between P5 and P10. mental Fig. $1 E-H$, available at www.neurosci.org as supplemental material). Similar observations were made at P20 with an increase in immunoreactivity within the barrels for Cx43 (Fig. 4G) and Cx30 (Fig. $4 F$ ), whereas such "patchy" pattern was not detected in other cortical regions examined at the level of layer IV (Fig. $4 H$ ). Immunostainings characteristic for gap junction plaques are shown in supplemental Fig. 1D,H (available at www.jneurosci.org as supplemental material). Finally, the pattern of expression of astrocytic Cxs, enriched in the barrels versus the septa, was also observed in tangential preparations as illustrated for $\mathrm{Cx} 43$ at $\mathrm{P} 10$ and for $\mathrm{Cx} 30$ at P20 (Fig. $4 E, H$, respectively). This typical pattern, characterized by an enriched expression of the two astrocytic Cxs within the barrels, was also observed in the adult for $\mathrm{Cx} 43$ and $\mathrm{Cx} 30$ in coronal as well as in tangential sections (Fig. $4 I-K$ ).

\section{Shaping of astrocytic networks in the barrel cortex}

Analysis of the spatial distribution of biocytin intercellular diffusion from the dialyzed astrocyte was performed to determine the shaping of gap junction-mediated communicating networks of astrocytes. Previous works have reported that dye injection in 

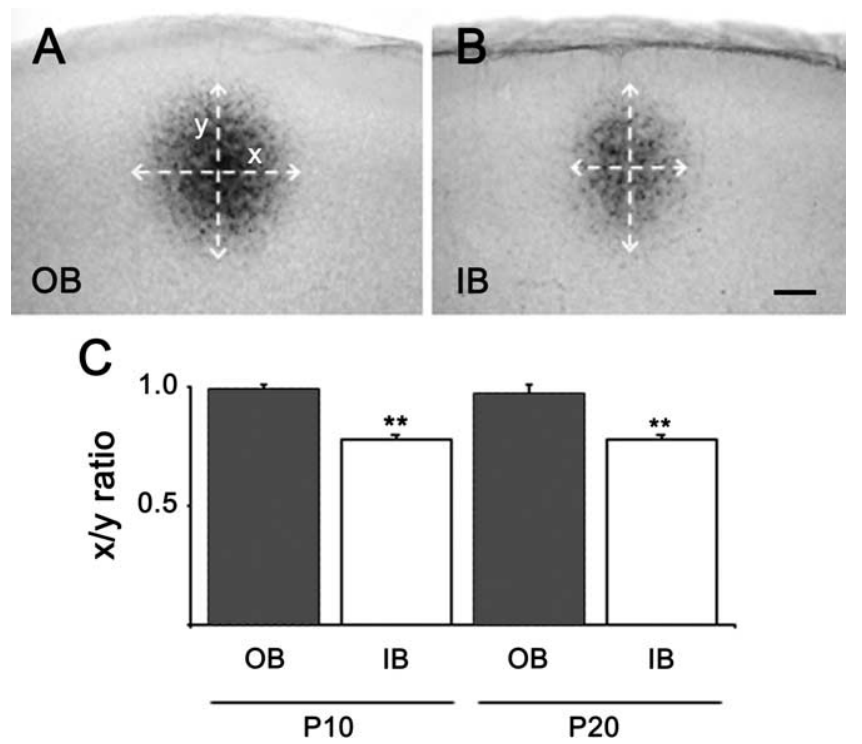

Figure 5. Shaping of astrocytic networks in the barrel cortex. $A, B$, Comparison of the shape of biocytin intercellular diffusion after injection performed at $\mathrm{P} 20$ in an astrocyte located in layer IV outside $(O B)(A)$ and within $(\mathrm{IB})(\boldsymbol{B})$ the barrel field. Dashed lines with arrowheads indicate the two axes ( $x$ and $y$ ) taken for the measurement of dye coupling. C, Summary diagram showing the comparison of dye coupling performed outside or in the barrel field at two developmental ages. This analysis of the shape of the coupling area was undertaken by considering two axes, $x$ and $y$, drawn in $\boldsymbol{A}$ and $\boldsymbol{B}$. The $x / y$ ratios were calculated from 3-10 independent experiments. ${ }^{* *} p<0.01$ between the $\mathrm{OB}$ and $\mathrm{IB}$ at both ages using unpaired $t$ test. Scale bar, $100 \mu \mathrm{m}$.

cortical astrocytes resulted in a circular coupling area (Binmöller and Müller, 1992; Houades et al., 2006), which, in three dimensions, corresponds to a spherical volume. Similar observations were made during this study when the astrocytes dialyzed with biocytin at P10 and P20 were located in the layer IV of the visual cortex (a region outside the barrel field) (Fig. 5A), where the number of coupled cells was $82 \pm 33(n=7)$ and $111 \pm 26(n=$ 3 ), respectively. In contrast, when this injection was performed in an astrocyte within the barrel cortex, the coupling area was oval (Fig. 5B), which, in three dimensions, corresponds to an oblate spheroidal volume. To validate this observation, characterization of the shape of the coupling area was achieved by defining two axes, $x$ and $y$, perpendicular and parallel to the surface of the cortex, respectively (Fig. $5 A, B$ ). As illustrated in Figure $5 C$, the $x / y$ ratio measured at $\mathrm{P} 10$ and $\mathrm{P} 20$ was $0.78 \pm 0.07(n=10)$ and $0.78 \pm 0.05(n=7)$, respectively, for the barrel cortex, compared with $0.99 \pm 0.05(n=7)$ and $0.97 \pm 0.07(n=3)$, respectively, for layer IV of the visual cortex. A similar ratio was obtained at P5 and P15 (0.84 $\pm 0.05, n=3$ and $0.79 \pm 0.08, n=8$, respectively) in the barrel cortex. As a whole, this two-dimensional (2D) analysis indicated that there is a bias toward spread in one direction and that within the barrel cortex intercellular diffusion of biocytin through gap junction channels is restricted in the transversal direction, i.e., from barrel to barrel.

\section{Shaping of astrocytic networks in transgenic mice with modified barrel organization}

We next examined whether the extent and the shaping of the astrocytic networks were affected when the barrel organization is disturbed by genetic engineering. The MAOA KO mouse was selected as a model in which barrels are lacking in the cerebral cortex, despite a normal patterning of the subcortical sensory relays (Cases et al., 1995). In addition, MAOA KO mice in which $5-\mathrm{HT}_{1 \mathrm{~B}}$ receptors were genetically removed resulted in a normal segregation of somatosensory projections that results in a normal barrel field in the cortex (Salichon et al., 2001). As illustrated in Figure 6, cytochrome oxidase staining performed at P10 indicated that barrels could clearly be observed in wild-type $\mathrm{C} 3 \mathrm{H} / \mathrm{HE}$ and in double $\mathrm{KO}$ mice, whereas they were lacking in the MAOA KO mice (Fig. $6 A_{1}-A_{3}$ ). This feature was also observed when the pattern of $\mathrm{Cx} 43$ expression was investigated in the same area at P10, with a clear difference of the level of expression in the barrel area compared with the septa (Fig. 6B). In contrast, such an expression pattern was not observed in the MAOA KO mice, where the expression of $\mathrm{Cx} 43$ was more homogenous in layer IV of the somatosensory cortex (Fig. 6C), localized in this mouse in reference to the shape, size, and orientation of the striatum. Interestingly, the compartmentalized $\mathrm{Cx} 43$ staining observed in wild-type mice was restored in double $\mathrm{KO}$ mice $(n=3)$.

Furthermore, the shape of astrocytic networks was investigated by performing biocytin injections in these three animal models. As described above, in the $\mathrm{P} 10$ wild-type $\mathrm{C} 3 \mathrm{H} / \mathrm{HE}$ mice, the coupling area obtained by injecting an astrocyte in the barrel cortex was not circular and exhibited a transversal restriction in dye diffusion $\left(x / y\right.$ ratio of $0.76 \pm 0.01 ; n=11$ ) (Fig. $\left.6 D_{1}\right)$. In contrast, in layer IV of the somatosensory cortex of P10 MAOA $\mathrm{KO}$ mice, the shape of the astrocytic network became more circular (Fig. $\left.6 D_{2}\right)$ with an $x / y$ ratio of $0.91 \pm 0.03(n=10)$ that was statistically different from that found in the wild type mice (Fig. $6 E)$. Furthermore, when biocytin injection was performed in $\mathrm{P} 10$ MAOA $\mathrm{KO} / 5-\mathrm{HT}_{1 \mathrm{~B}}$ receptor $\mathrm{KO}$ mice, the coupling area was increased by $52 \%(n=15)$ compared with control animals. Moreover, in these animals the $x / y$ ratio was $0.85 \pm 0.01(n=15)$, indicating a transversal restriction statistically different from that obtained from the MAOA KO mice (Fig. 6E). From these observations a correlation was made between the presence of a detectable barrel organization, a differential level of Cx43 expression between barrels and septa characterized by a weaker expression level in the septa, and the shape of the astrocytic network, characterized by a transversal restriction of the intercellular diffusion of biocytin.

\section{Dye-coupling orientation within a barrel}

A further step in characterizing the spatial properties of dye coupling through astrocytic networks in the barrel cortex was to correlate the location of the injection site with the intercellular spread of the dye within a single barrel. This was achieved at P10, an age at which the barrels can be directly observed easily with DIC optics and infrared illumination of coronal acute slices. Furthermore, dye coupling was studied with sulforhodamine B and visualized under epifluorescence. The use of this dye allowed direct observation and offered the advantage to superimpose the dye-coupling area with DIC observation of the barrels (Fig. $7 A_{1}$ ). This study was performed by taking into account the shape of the dye-coupling area in regard to the location of the injected astrocyte within the barrel itself (Fig. $7 A_{1}$ ). For this purpose, the distance of dye diffusion from the site of injection was measured following two directions, i.e., toward the wall and the center of the barrel, $d_{\mathrm{w}}$ and $d_{\mathrm{c}}$, respectively (Fig. $7 A_{2}$ ). As illustrated in Figure $7 B$, three categories were then distinguished depending on the location of the injection site. In addition, as the size of each barrel was not equivalent, the location of the injection site was expressed in reference to the normalized size of the studied barrel. Accordingly, each injection was defined as belonging to one of three distinct parts of a barrel: those performed at a distance up to $10 \%$ of the total barrel size starting from the nearest barrel wall, trials performed at a distance ranging from 10 to $25 \%$ and injec- 

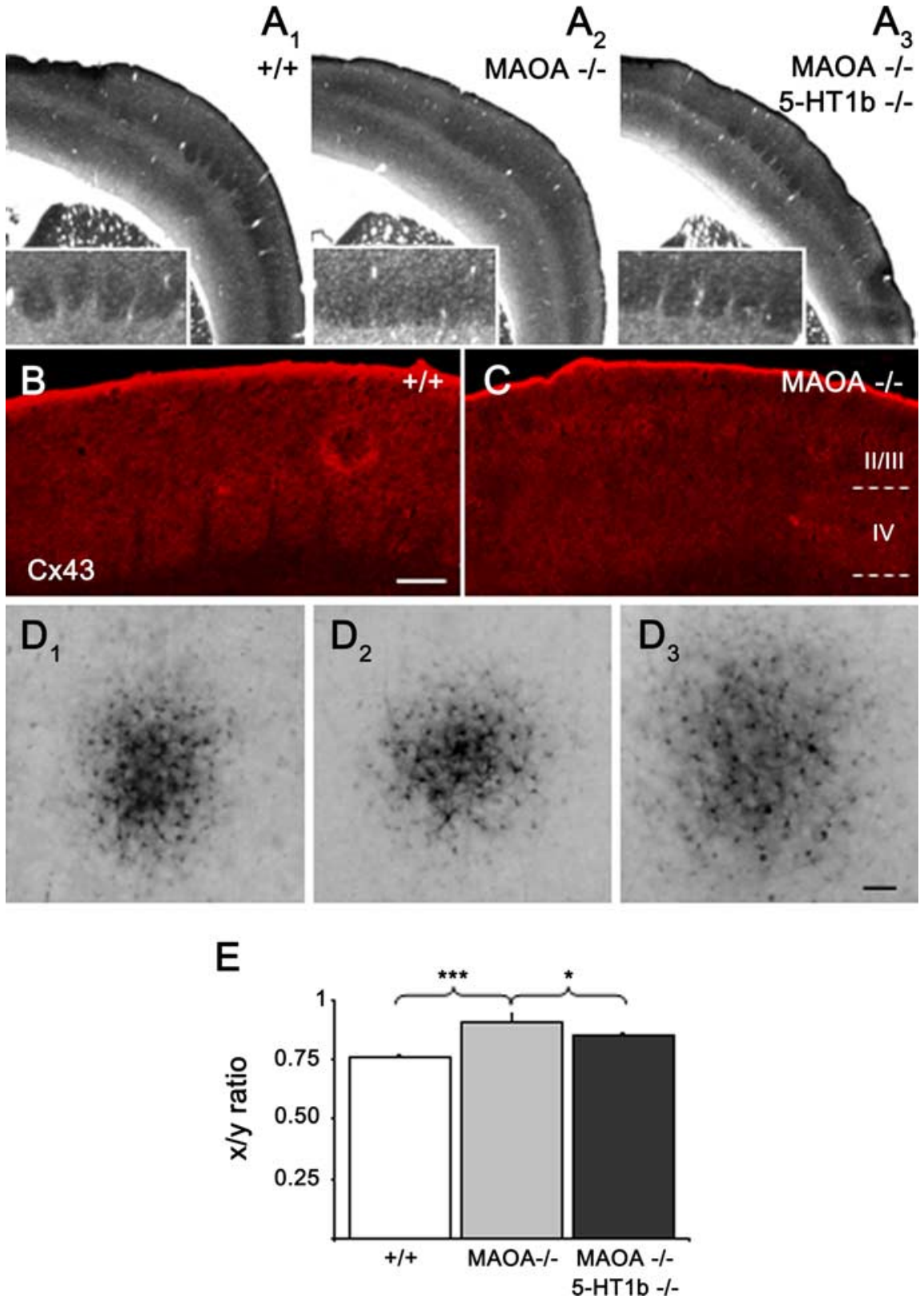

Figure 6. Shaping of astrocytic networks in the layer IV of the somatosensory cortex from transgenic mice with modified barrel organization. $A_{1}-A_{3}$, Cytochrome c staining revealing the presence or the absence of a barrel field organization in frontal slices from wild-type $\mathrm{C} 3 \mathrm{H} / \mathrm{HE}, \mathrm{MAOA} \mathrm{KO}$, and $\mathrm{MAOA} / 5-\mathrm{HT}_{1 \mathrm{~B}} \mathrm{KO}$ mice studied at $\mathrm{P} 10$. The insets show a higher magnification of layer IV in these slices with detectable barrels in the wild-type and the double $\mathrm{KO}$ mice and the lack of compartmentalization in the MAOA KO mouse. For the MAOA KO, the location of the somatosensory cortex was defined in reference to the shape and size of the striatum being part of the slice. $B, C, C \times 43$ immunostaining of frontal sections at P10. $\boldsymbol{B}$, In wild type, Cx43 is compartmentalized in the barrel field. $\boldsymbol{C}$, In contrast, a uniform distribution of $\mathrm{C} \times 43$ immunoreactivity is observed in the somatosensory cortex of MAOA KO mice. $\boldsymbol{D}_{\mathbf{1}}-\boldsymbol{D}_{\mathbf{3}}$, Shape of the dye-coupling area after biocytin injection of an astrocyte located in the barrel field of the wild-type $\left(\boldsymbol{D}_{1}\right)$, the MAOA $\left(\boldsymbol{D}_{2}\right)$, and the double KO MAOA/5-HT $1 \mathrm{~B}$ receptor $\left(\boldsymbol{D}_{3}\right)$ mice studied at P10. $\boldsymbol{E}$, Summary diagram of the $x / y$ ratio calculated from $3-10$ independent experiments. ${ }^{* * *} p<0.001$ between wild type and MAOA KO using ANOVA test analysis; $\mathrm{MAOA} / 5-\mathrm{HT}_{1 \mathrm{~B}}$ receptor was different at ${ }^{*} p<0.05$ from MAOA KO, whereas there is no statistical difference between $\mathrm{MAOA} / 5-\mathrm{HT}_{1 \mathrm{~B}}$ receptor and wild type. Scale bars: $\boldsymbol{B}$ (for $\left.\boldsymbol{B}, \boldsymbol{C}\right), \boldsymbol{D}, 100 \mu \mathrm{m}$.

tions made at a distance ranging between 25 and 50\% (50\% being the center of the barrel). Then, for each category, the distance of the dye diffusion was measured in the two directions arbitrarily defined above, $d_{\mathrm{c}}$ and $d_{\mathrm{w}}$. When such analysis was achieved, it appeared that dye spread was asymmetric with a facilitation of diffusion toward the barrel center compared with the periphery. This asymmetry was found to be statistically significant as the injection site became closer to the barrel wall (Fig. 7B). These measurements also indicated that dye coupling was higher as the injection site was closer to the barrel center, indeed the distance of dye diffusion almost doubled when the injection site was performed close to the center $(25-50 \%)$ compared with the wall $(0-10 \%)$. This analysis was completed by plotting the number of coupled cells versus the diffusion ratio $d_{\mathrm{c}} / d_{\mathrm{w}}$ (Fig. 7C). Such plot indicates that the number of coupled cells was increased as the $d_{\mathrm{c}} / d_{\mathrm{w}}$ ratio approached 1 , demonstrating that the diffusion asymmetry caused by the vicinity of the barrel wall is responsible for confinement of dye coupling within the barrel.

Moreover, based on 32 injections performed with sulforhodamine $B$, either within a barrel (Fig. $\left.8 A_{1}, A_{2}\right)$ or in a septum (Fig. $8 B_{1}, B_{2}$ ), clear differences in dyecoupling properties were observed. When the injected astrocyte was located within a barrel, the incidence of coupling was $85 \%$ $(n=20)$, although it fell to $25 \%(n=12)$ when the recording was performed in a septum. Moreover, the average number of coupled cells was $15 \pm 1(n=17)$ and $3 \pm$ $1(n=3)$ for the barrel and the septum, respectively (Fig. 8C). When compared with the experiments performed with biocytin, the amount of dye coupling was reduced with sulforhodamine B, although recording times (20 min) used for cell dialysis were kept similar (supplemental Fig. $2 A, B$, available at www.jneurosci.org as supplemental material). Moreover, in most trials (92\%; $n=17)$ dye coupling was limited to the injected barrel. Interestingly, the analysis of the electrophysiological properties of the recorded astrocytes indicated that all astrocytes $(n=12)$ recorded in the septum region exhibited passive properties (Fig. $8 A_{2}, B_{2}$, traces), whereas the identification of astrocytes recorded within a barrel gave the following proportion: $96 \%$ PAs, 3\% IGs, and 1\% CGs. No difference was found in the membrane potential $(-85 \pm 4 \mathrm{mV}$, $n=21$ and $-88 \pm 4 \mathrm{mV}, n=12$, for barrel and septum, respectively) and the input resistance $(44.5 \pm 5.3 \mathrm{M} \Omega, n=21$ and $39.6 \pm 7.2 \mathrm{M} \Omega, n=12$, for barrel and septum, respectively). Furthermore, the analysis of the morphology of biocytin- or sulforhodamine B-injected astrocytes did not indicate difference when the cells were located in a barrel or within a septum (Fig. 8, 9). In both cases, confocal analysis indicated that the stained cells exhibited a typical shape of protoplasmic astrocytes with similar dimensions for the domain defined by their processes (Fig. $9 A_{1}, B$ ). The examination of coupled astrocytes indicated that their morphology was similar whatever their location in the coupling area. In addition, there was no overlap between their respective domains indicating 
that they were juxtaposed rather than imbricated (Fig. 9A $)$. Altogether, these results indicate that the differences in the coupling properties of the astrocytes located within the barrels versus the septa were not correlated with distinct subpopulations of astrocytes classified on the basis of their electrophysiological and morphological properties. Finally, this analysis and the observations illustrated in Figure 7 indicate that the presence of uncoupled astrocytes within the septa shapes the intercellular diffusion in the astrocyte network within a defined barrel.

\section{Discussion}

Altogether, the above findings demonstrate that, in layer IV of the somatosensory cortex, gap junctions composed by $\mathrm{Cx} 43$ and $\mathrm{Cx} 30$ underlie intercellular communication between astrocytes. These communicating networks are mainly constituted by astrocytes because after the initial loading of an astrocyte, identified by its morphological and electrophysiological properties, neither NeuN- nor NG2-positive cells were found to be coupled. In addition, although immunostaining with GFAP antibodies and GFAP-eGFP labeling resulted in a rather low percentage of cells identified as astrocytes because of the well known low level of GFAP expression in astrocytes from the cerebral cortex of the mouse (Nimmerjahn et al., 2004; Houades et al., 2006; Wilhelmsson et al., 2006), a high percentage of coupled cells was found to be S100-positive (90\%). Although S100 expression is seen predominantly in astrocytes, it may also be expressed in subpopulations of central neurons and oligodendrocytes (Rickmann and Wolff, 1995a,b). However, as no overlapping of S100 and NeuN immunoreactivity was detected in double-staining experiments performed with these two markers, this observation excludes S100 staining of neurons in the barrel cortex. In addition, the morphological analysis of biocytinpositive cells pointed out the lack of heterotypic coupling with cells having the typical morphology of differentiated oligodendrocytes. Consequently, dye-coupling experiments presented here allow revealing the network organization of coupled astrocytes.

The analysis of the 2D spatial organization of such networks indicates the occurrence of a marked transversal (barrel to barrel) restriction in layer IV of the somatosensory cortex. This contrasts with previous studies performed in the visual cortex where dye coupling was found to be circular (Binmöller and Müller, 1992; Houades et al., 2006). Furthermore, the extent of dye spread was found to be very different with biocytin and sulforhodamine B, indeed $73 \pm 17(n=10)$ and $15 \pm 1(n=17)$ coupled cells were monitored at P10, respectively (supplemental Fig. 2, available at www.jneurosci.org as supplemental material). The restricted communication between two barrels was exacerbated when sulforhodamine B was used as intercellular tracer because dye coupling was found to be limited to a barrel. As the constraint exerted on the intercellular diffusion of this dye was more pronounced, dye-coupling properties could be studied within a single barrel. This analysis indicated that the particular shaping of the coupling area found in the barrel cortex could be attributed to at least two properties: (1) coupled astrocytes located within a barrel exhibit a preferential orientation of dye coupling toward the center of the barrel, and (2) the presence of astrocytes that are not, or weakly, coupled in the interbarrel space. These findings indicate that, in this brain region characterized by a strong anatomofunctional neuronal compartmentalization, astrocytes also exhibited a specific spatial organization and are constituted by several subpopulations with distinct coupling properties favoring intercellular communication within the barrel rather than between two neighboring barrels. In the septa, uncoupled astrocytes exhibit passive electrophysiological properties suggesting that in the somatosensory cortex, in contrast to the hippocampus (Matthias et al., 2003; Wallraff et al., 2004, Schools et al., 2006), there are subpopulations of PAs with different coupling properties.

During the last decade, our view of the morphology of a single astrocyte and its organization within groups of astrocytes has greatly changed. Indeed, from an initial concept of stellate and "interdigitated" astrocytes (Rolhmann and Wolff, 1996), those of "spongiform" and astrocytic domain have emerged recently (Bushong et al., 2002; Ogata and Kosaka, 2002). From these studies, it is clear that the area of contact between adjacent astrocytes is relatively reduced which limits de facto the area available for 

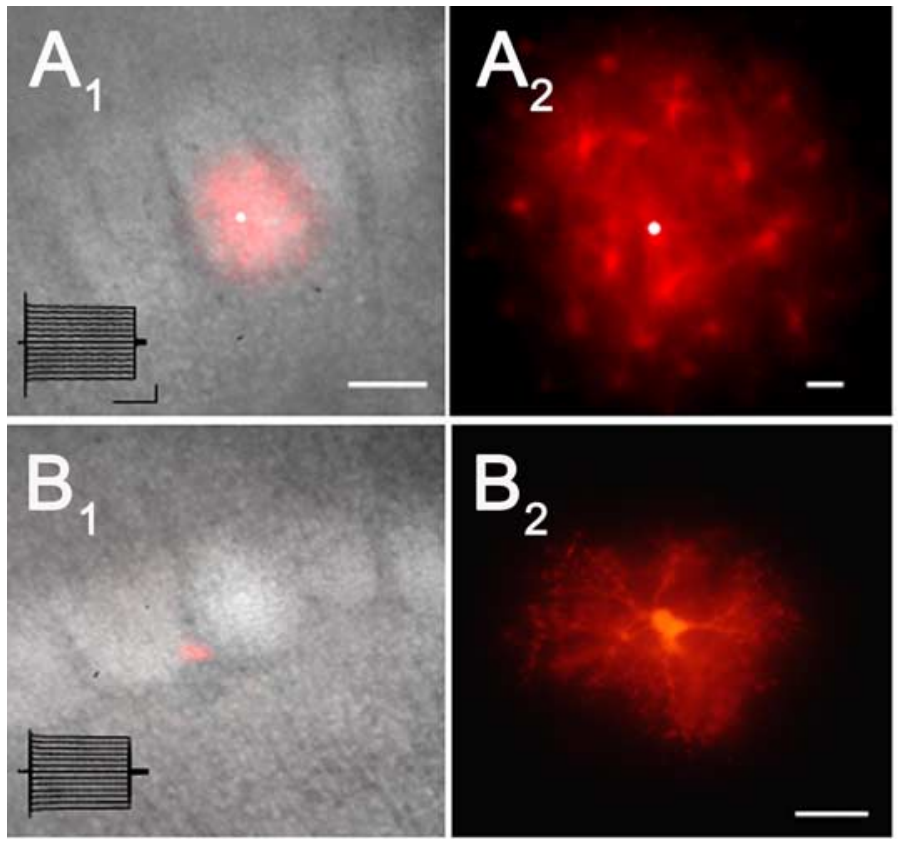
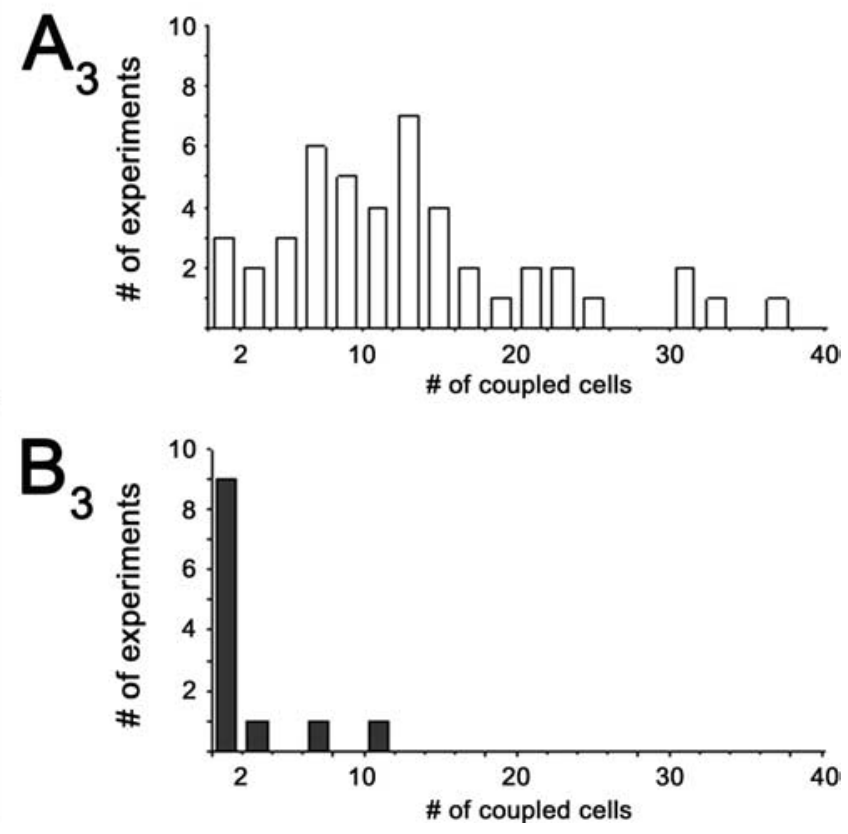

Figure 8. Differential coupling properties of astrocytes in the barrel cortex. $\boldsymbol{A}_{\mathbf{1}}-\boldsymbol{B}_{\mathbf{2}}$, Direct observation of sulforhodamine $B$ injections performed at $P 10$ in astrocytes located either in a barrel or in a septum. $A_{1}$, Superposition of photomicrographs captured under Nomarski optic and epifluorescence showing the extent of dye spread after 20 min recording and the location of the coupling area within the barrel. $\boldsymbol{A}_{2}$, High-magnification fluorescent image showing the shape of the dye coupling and the detail of the cells involved in this process. $\boldsymbol{B}_{\boldsymbol{1}}$, Superposition of photomicrographs showing the lack of dye coupling and the location of the astrocyte recorded in the septum. $\boldsymbol{B}_{2}$, High-magnification image showing the shape of the recorded cells. Scale bars: $\boldsymbol{A}_{\boldsymbol{1}}, \boldsymbol{B}_{\boldsymbol{1}}, 150 \mu \mathrm{m} ; \boldsymbol{A}_{\mathbf{2}}$ $\boldsymbol{B}_{2}, 20 \mu \mathrm{m} . \boldsymbol{A}_{1}, \boldsymbol{B}_{1}$, Insets, Family of current traces recorded in response to voltage steps of $150 \mathrm{~ms}$ pulses ranging from -180 to $+40 \mathrm{mV}$ with $10 \mathrm{mV}$ increments, applied at a holding potential of $80 \mathrm{mV}$. Note that the two recorded astrocytes were characterized by similar passive properties. $\boldsymbol{A}_{\mathbf{3}}, \boldsymbol{B}_{\mathbf{3}}$, Summary diagrams of dye injections performed at P10 with the two different sites of recording, i.e., in the barrel (white columns) or in the septum (black columns).

gap junctions. When astrocytes were examined from dyecoupling experiments in the barrel field, this notion of astrocytic domains was also clearly visible (Fig. 9A,B). Consequently, in addition to their individual domain organization, the network organization of astrocytes contributed by subpopulations with defined coupling properties adds a second level of complexity in their overall organization.

In the somatosensory cortex, the shaping of dye coupling fits well with the pattern of expression of $\mathrm{Cx} 43$ and Cx30. Indeed, the expression of these two Cxs is enriched within the barrels compared with the septa, which may account for the high proportion of noncoupled astrocytes in the interbarrel space. What governs such pattern of Cxs expression and the shaping of the coupling area in the barrel field is an important question. One way to address this question was to use transgenic mice with modified barrel organization. Indeed, the transversal restriction of the dyecoupling area was not observed in the MAOA KO mouse, although this typical shape was restored in the double transgenic mouse MAOA/5- $\mathrm{HT}_{1 \mathrm{~B}}$ receptor. In the MAOA KO mouse, granular cells form a continuous band in layer IV, whereas they are clustered and form barrels in the wild-type (Cases et al., 1995). This indicated that there is a neuronal reorganization in the somatosensory cortex in this mouse without barrels. In the double knock-out MAOA/5- $\mathrm{HT}_{1 \mathrm{~B}}$ receptor, the barrel cytoarchitecture with a partial segregation of the neuronal organization is restored allowing visualizing neuronal compartments (Salichon et al., 2001). Altogether, these findings demonstrated that the shaping of gap junction-mediated pathways between astrocytes is tightly linked to the neuronal organization in the somatosensory cortex. The difference in the shaping of astrocytic networks in wild-type and $\mathrm{KO}$ animals could be attributable to either the absence of neuronal clustering in the MAOA KO and/or to a change in neu- ronal activity. In the MAOA KO mouse, it has been reported that although the barrels are absent, the segregation of information processing is still present with functional columns (Yang et al., 2001). This finding suggests that in the somatosensory cortex neuronal clustering rather than neuronal activity likely accounts for the shaping of astrocytic networks. Indeed, the clustering of neurons forming the barrel walls may constitute a diffusion barrier for the astrocytic networks. How such barrier affects connexin expression remains to be studied in more detail. One possibility is that astrocytes located in the septa have a different morphology with, for instance, a reduced arborization and less contact areas between their processes. However, the analysis of the morphology of biocytin- or sulforhodamine B-injected astrocytes indicated that this is not the case (Fig. 9). Alternatively, a difference in the density of astrocytes in the septa compared with the barrels could also explain the pattern of Cx expression. However, none of such difference was detected with GFAP or S100 staining or in GFAP-eGFP mice. Finally, the compartmentalized expression of Cxs could be attributable to a difference in the expression of extracellular matrix and/or adhesion molecules reported to occur in the barrel cortex, as for instance the perineuronal net (McRae et al., 2007) or cadherins (Gil et al., 2002). Indeed, such compartmentalized pattern could affect the expression of astrocytic Cxs and GJC because proteoglycans (Spray et al., 1987) and cadherins (Giepmans, 2004) have been reported to control Cx expression and function.

In summary, this study provides evidence that in a cortical area characterized by topographic neuronal maps, astrocytes are also organized as communicating networks that overlap neuronal compartments. Because coupled astrocytes are those expressing glutamate transporters (Matthias et al., 2003; Wallraff et al., 2004; Schools et al., 2006), our finding completes a previous work 

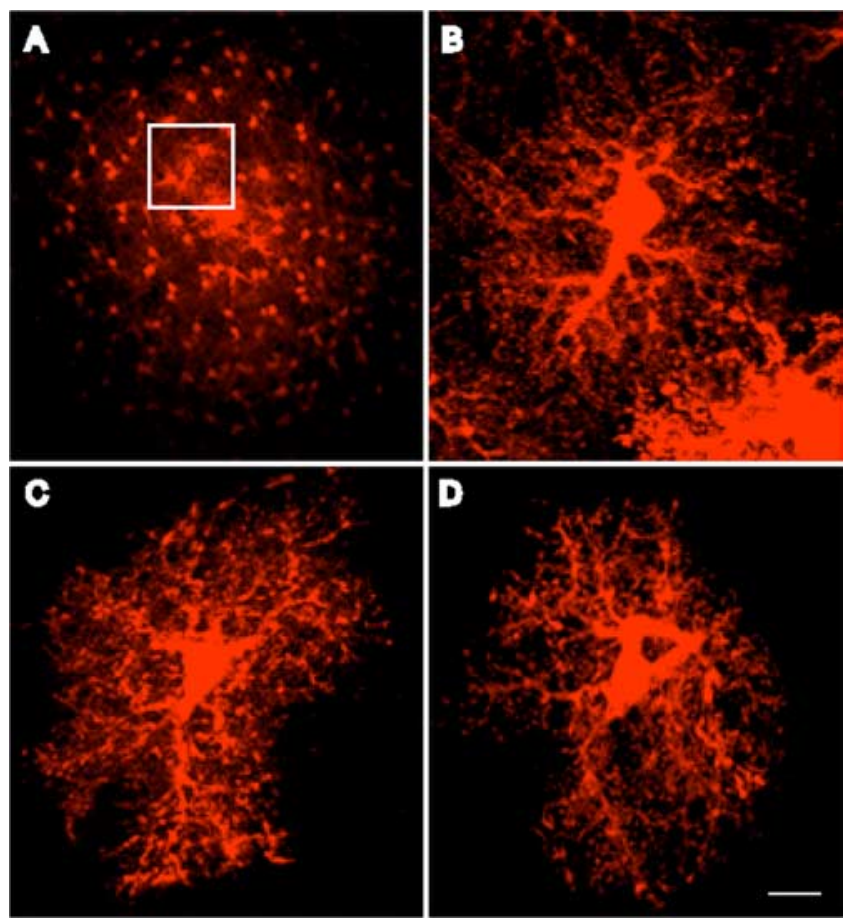

Figure 9. Confocal analysis of the morphology of stained astrocytes located in a barrel or in a septum. $\boldsymbol{A}$, Low magnification of the dye-coupling area after the recording of an astrocyte located in a barrel with a patch pipette filled with biocytin. The inset delineates a region shown at a higher magnification in $\boldsymbol{B}$. $\boldsymbol{B}$, Projection of 10 optical sections $(1 \mu \mathrm{m})$ showing the morphology of one stained cell typical of protoplasmic astrocytes and its organization in individual domain. $C, D$, Examples of the morphology of astrocytes loaded with sulforhodamine B located in septa. Note that the feature of these astrocytes, as well as the domains defined by their processes, were similar to those of the astrocyte illustrated in $\boldsymbol{B}$. Scale bar: (in D) $\boldsymbol{A}, 50 \mu \mathrm{m} ; \boldsymbol{B}-\boldsymbol{D}$, $10 \mu \mathrm{m}$.

showing an enriched expression of astrocyte glutamate transporters in the barrels (Voutsinos-Porche et al., 2003). Moreover, in vivo calcium responses in astrocytes (Wang et al., 2006), as well as astrocytic coverage and glutamate transporter expression (Genoud et al., 2006), depend on neuronal activity in the barrel cortex. Accordingly, it becomes essential to consider astrocytic properties and neuroglial interaction to fully understand the mechanisms underlying processing in neuronal maps. In the barrel cortex, we demonstrate that GJC in astrocytes is favored within a barrel rather than between two adjacent barrels. This observation suggests that communicating astrocytes may contribute to the confinement of neuroglial interaction within a defined barrel as reported for excitatory neuronal networks (Petersen and Sakmann, 2000). However, such statement does not seem to apply for calcium signaling because it was reported previously that coupling via gap junctions is not a prerequisite for astrocytes to respond to electrical stimulations (Schipke et al., 2008). Alternatively, the shaping of GJC in the barrel cortex could exert a spatial limitation on the extent of other processes in which astrocytic gap junctions have been proposed to participate, such as bystander death in the setting of injury or functional hyperemia (Iadecola and Nedergaard, 2007). Interestingly, the activation of a single cortical barrel by whisker stimulation was reported to induce flow changes in a columnar manner overlapping neuronal activity and defining "vascular modules" (Woolsey et al., 1996). As at the neurovascular interface astrocytes are a key element that control blood flow (Iadecola, 2004; Haydon and Carmignoto, 2006), their network organization could also contribute to define such vascular responses.

\section{References}

Binmöller FJ, Müller CM (1992) Postnatal development of dye-coupling among astrocytes in rat visual cortex. Glia 6:127-137.

Blomstrand F, Venance L, Siren AL, Ezan P, Hanse E, Glowinski J, Ehrenreich $\mathrm{H}$, Giaume C (2004) Endothelins regulate astrocyte gap junctions in rat hippocampal slices. Eur J Neurosci 19:1005-1015.

Bushong EA, Martone ME, Jones YZ, Ellisman MH (2002) Protoplasmic astrocytes in CA1 stratum radiatum occupy separate anatomical domains. J Neurosci 22:183-192.

Cases O, Seif I, Grimsby J, Gaspar P, Chen K, Pournin S, Muller U, Aguet M, Babinet C, Shih JC, De Maeyer E (1995) Aggressive behavior and altered amounts of brain serotonin and norepinephrine in mice lacking MAOA. Science 268:1763-1766.

Chvatal A, Pastor A, Mauch M, Sykova E, Kettenmann H (1995) Distinct populations of identified glial cells in the developing rat spinal cord slice: ion channel properties and cell morphology. Eur J Neurosci 7:129-142.

D’Ambrosio R, Wenzel J, Schwartzkroin PA, McKhann II GM, Janigro D (1998) Functional specialization and topographic segregation of hippocampal astrocytes. J Neurosci 18:4425-4438.

Genoud C, Quairiaux C, Steiner P, Hirling H, Welker E, Knott GW (2006) Plasticity of astrocytic coverage and glutamate transporter expression in adult mouse cortex. PLoS Biol 4:e343.

Giepmans BN (2004) Gap junctions and connexin-interacting proteins. Cardiovasc Res 62:233-245.

Gil OD, Needleman L, Huntley GW (2002) Developmental patterns of cadherin expression and localization in relation to compartmentalized thalamocortical terminations in rat barrel cortex. J Comp Neurol 453:372-388.

Haydon PG, Carmignoto G (2006) Astrocyte control of synaptic transmission and neurovascular coupling. Physiol Rev 86:1009-1031.

Houades V, Rouach N, Ezan P, Kirchhoff F, Koulakoff A, Giaume C (2006) Shaping of gap junction-mediated astrocyte networks in the cortex and the hippocampus of the mouse. Neuron Glia Biol 2:3-14.

Iadecola C (2004) Neurovascular regulation in the normal brain and in $\mathrm{Alz}$ heimer's disease. Nat Rev Neurosci 5:347-360.

Iadecola C, Nedergaard M (2007) Glial regulation of the cerebral microvasculature. Nat Neurosci 10:1369-1376.

Matthias K, Kirchhoff F, Seifert G, Huttmann K, Matyash M, Kettenmann H, Steinhauser C (2003) Segregated expression of AMPA-type glutamate receptors and glutamate transporters defines distinct astrocyte populations in the mouse hippocampus. J Neurosci 23:1750-1758.

McRae PA, Rocco MM, Kelly G, Brumberg JC, Matthews RT (2007) Sensory deprivation alters aggrecan and perineuronal net expression in the mouse barrel cortex. J Neurosci 27:5405-5413.

Mugnaini E (1986) Cell junctions of astrocytes, ependyma, and related cells in the mammalian central nervous system, with emphasis on the hypothesis of a generalized functional syncytium of supporting cells. In: Cellular neurobiology: A series (Fedoroff S, Vernadakis A, eds), pp 329-371. Orlando, FL: Academic.

Nagy JI, Rash JE (2000) Connexins and gap junctions of astrocytes and oligodendrocytes in the CNS. Brain Res Brain Res Rev 32:29-44.

Nimmerjahn A, Kirchhoff F, Kerr JN, Helmchen F (2004) Sulforhodamine 101 as a specific marker of astroglia in the neocortex in vivo. Nat Methods $1: 31-37$.

Nolte C, Matyash M, Pivneva T, Schipke C, Ohlemeyer C, Hanisch UK, Kirchhoff F, Kettenmann H (2001) GFAP promoter-controlled EGFPexpressing transgenic mice: a tool to visualize astrocytes and astrogliosis in living brain tissue. Glia 33:72-86.

Ogata K, Kosaka T (2002) Structural and quantitative analysis of astrocytes in the mouse hippocampus. Neuroscience 113:221-233.

Petersen CC, Sakmann B (2000) The excitatory neuronal network of rat layer 4 barrel cortex. J Neurosci 20:7579-7586.

Pfrieger FW, Barres BA (1997) Synaptic efficacy enhanced by glial cells in vitro. Science 277:1684-1687.

Rebsam A, Seif I, Gaspar P (2002) Refinement of thalamocortical arbors and emergence of barrel domains in the primary somatosensory cortex: a study of normal and monoamine oxidase a knock-out mice. J Neurosci 22:8541-8552.

Rickmann M, Wolff JR (1995a) S100 immunoreactivity in a subpopulation of oligodendrocytes and Ranvier's nodes of adult rat brain. Neurosci Lett 186:13-16.

Rickmann M, Wolff JR (1995b) Modifications of S100-protein immunore- 
activity in rat brain induced by tissue preparation. Histochem Cell Biol 103:135-145.

Rolhmann A, Wolff JR (1996) Subcellular topography and plasticity of gap junction distribution on astrocytes. In: Gap junctions in the nervous system (Spray DC, Dermietzel R, eds), pp 175-1992. Austin, TX: R. G. Landes.

Rouach N, Glowinski J, Giaume C (2000) Activity-dependent neuronal control of gap-junctional communication in astrocytes. J Cell Biol 149:1513-1526.

Rouach N, Koulakoff A, Giaume C (2004) Neurons set the tone of gap junctional communication in astrocytic networks. Neurochem Int 45:265-272.

Salichon N, Gaspar P, Upton AL, Picaud S, Hanoun N, Hamon M, De Maeyer E, Murphy DL, Mossner R, Lesch KP, Hen R, Seif I (2001) Excessive activation of serotonin $(5-\mathrm{HT}) 1 \mathrm{~B}$ receptors disrupts the formation of sensory maps in monoamine oxidase a and 5-ht transporter knock-out mice. J Neurosci 21:884-896.

Schipke C, Haas B, Kettenmann H (2008) Astrocytes discriminate and selectively respond to the activity of subpopulation of neurons within the barrel cortex. Cereb Cortex, in press.

Schools GP, Zhou M, Kimelberg HK (2006) Development of gap junctions in hippocampal astrocytes: evidence that whole cell electrophysiological phenotype is an intrinsic property of the individual cell. J Neurophysiol 96:1383-1392.

Spray DC, Fujita M, Saez JC, Choi H, Watanabe T, Hertzberg E, Rosenberg LC, Reid LM (1987) Proteoglycans and glycosaminoglycans induce gap junction synthesis and function in primary liver cultures. J Cell Biol 105:541-551.

Theis M, Sohl G, Eiberger J, Willecke K (2005) Emerging complexities in identity and function of glial connexins. Trends Neurosci 28:188-195.

Verkhratsky A, Toescu EC (2006) Neuronal-glial networks as substrate for CNS integration. J Cell Mol Med 10:826-836.

Volterra A, Meldolesi J (2005) Astrocytes, from brain glue to communication elements: the revolution continues. Nat Rev Neurosci 6:626-640.
Voutsinos-Porche B, Knott G, Tanaka K, Quairiaux C, Welker E, Bonvento G (2003) Glial glutamate transporters and maturation of the mouse somatosensory cortex. Cereb Cortex 13:1110-1121.

Wallraff A, Odermatt B, Willecke K, Steinhauser C (2004) Distinct types of astroglial cells in the hippocampus differ in gap junction coupling. Glia 48:36-43.

Wang X, Lou N, Xu Q, Tian GF, Peng WG, Han X, Kang J, Takano T, Nedergaard M (2006) Astrocytic $\mathrm{Ca}^{2+}$ signaling evoked by sensory stimulation in vivo. Nat Neurosci 9:816-823

Wilhelmsson U, Bushong EA, Price DL, Smarr BL, Phung V, Terada M, Ellisman MH, Pekny M (2006) Redefining the concept of reactive astrocytes as cells that remain within their unique domains upon reaction to injury. Proc Natl Acad Sci USA 103:17513-17518.

Wong-Riley MT, Welt C (1980) Histochemical changes in cytochrome oxidase of cortical barrels after vibrissal removal in neonatal and adult mice. Proc Natl Acad Sci USA 77:2333-2337.

Woolsey TA, Van der Loos H (1970) The structural organization of layer IV in the somatosensory region (SI) of mouse cerebral cortex. The description of a cortical field composed of discrete cytoarchitectonic units. Brain Res 17:205-242.

Woolsey TA, Rovainen CM, Cox SB, Henegar MH, Liang GE, Liu D, Moskalenko YE, Sui J, Wei L (1996) Neuronal units linked to microvascular modules in cerebral cortex: response elements for imaging the brain. Cereb Cortex 6:647-660

Yamamoto T, Vukelic J, Hertzberg EL, Nagy JI (1992) Differential anatomical and cellular patterns of connexin43 expression during postnatal development of rat brain. Brain Res Dev Brain Res 66:165-180.

Yang Z, Seif I, Armstrong-James M (2001) Differences in somatosensory processing in $\mathrm{S} 1$ barrel cortex between normal and monoamine oxidase $\mathrm{A}$ knockout (Tg8) adult mice. Cereb Cortex 11:26-36.

Zhou M, Schools GP, Kimelberg HK (2006) Development of GLAST(+) astrocytes and NG2 $(+)$ glia in rat hippocampus CA1: mature astrocytes are electrophysiologically passive. J Neurophysiol 95:134-143. 